Psychiatric Bulletin (2000), 24, 401-402

\title{
TOM BURNS
}

\section{Supervised discharge orders ${ }^{\dagger}$}

Donna Franklin and her colleagues (2000, this issue) report on how psychiatrists are using supervised discharge orders (SDOs) and their preliminary estimates of how well they work. Two things stand out from the paper that mirror my local experience. First, there is no consistency in their use - only one general adult psychiatrist in four has a single patient on an SDO. Among those psychiatrists who were using the order, over one-third had more than one patient subject to it. Second, SDOs are being used as substitutes for community treatment orders (CTOs). The most common reason for applying them was to increase compliance with medication, and in over $40 \%$ of patients who had been on the order for over 2 months their psychiatrists judged that it had achieved an improvement in taking medicines.

This 'compulsion by postcode' is likely to be more marked now than this paper suggests. The study was conducted when the order was still fairly new. Of those who had tried SDOs, 77\% judged them helpful or very helpful and only $10 \%$ 'not helpful'. When I responded to the questionnaire, four patients in my assertive outreach team were subject to the order and I judged it 'very helpful'. I now have nine patients on SDOs. Probably most of the $75 \%$ of psychiatrists with no patients on SDOs still have none. Such a variation in practice cannot make sense. The profession has correctly identified the conflict between supervision and treatment, which is at the heart of the issue and is glossed over in the legal construct. This ambiguity (repeatedly confirmed when completing the recommendations for Section 25 of the Mental Health Act 1983 with weasel words such as 'to permit access to encourage and support maintenance medication') will continue to foster inconsistency of practice and inhibit frank and honest debate.

Does it matter anyway? If CSOs are beginning to achieve the proposed aim of CTOs without their associated conflict should we not just keep our heads down and wait until good (or bad) practice spreads? I think it does matter. The SDO experience reported by Franklin et al helps bring rhetoric and reality closer together.

A significant minority of psychiatrists recognise that using persuasion (backed up by the formality of a legal structure) is of real value for a small minority of patients. They are not alone in this. The College's proposal for a

†See pp. 412-415, this issue. 'community supervision order' (Royal College of Psychiatrists, 1993) embodied such a provision for patients with an established pattern of repeated relapse secondary to non-compliance. Even more surprisingly, members of the National Schizophrenia Fellowship endorsed the idea. In their survey of 2300 respondents (54\% with direct experience of compulsory treatment either as recipient or carer), 58\% considered there was a limited role for a CTO (National Schizophrenia Fellowship, 1999). If compulsion is to be used, then it should be organised to provide the maximum benefit and minimise disruption for the patient, and should therefore not necessarily be restricted to inpatient care.

There are complex reasons why the College's proposal failed. One of them, undoubtedly, was the lack of conviction conveyed by using the term 'community supervision order', rather than acknowledging it as a community treatment order and arguing more closely exactly what this would mean in practice.

It is crucial for a profession such as ours to be open and honest. Our success or failure, both with our patients and their families and also with society at large, depends on being able to develop a relationship of trust. To do so requires that we listen carefully and explain clearly what we propose to do and why. This is even more important when we use compulsion (a small, but essential part of mental health services in all developed societies). The temptation to fudge the issue, either with the patient or in national negotiations, can appear attractive in the short term to avoid distress or conflict. In the longer term a high price is paid when such duplicity becomes clear, as it inevitably will.

It is a pity that Franklin et al do not try to explore why the SDOs seem to work. It cannot simply be the threat of recall. In my own service we have only used this twice (although with good effects on both occasions). All of my patients know that they cannot be compelled to take medicines - I always tell them, and so does our legal advice centre and the tribunals. Indeed, one of my patients insists on gleefully reminding me of this nearly every time we meet. Yet he takes his medicine and has remained well for nearly 2 years, despite never having cooperated before when out of hospital. Both he and his wife attribute the change in his behaviour to the SDO! Relationships can be respectful, even warm, without 
an

editorials necessarily being equal. We, of all professions, should be familiar with the complexity of human nature and relationships. Perhaps the SDO is perceived as a statement of commitment by the psychiatrist. Understanding who complies with SDOs, and why, might inform the ongoing debate about a possible CTO.

This work has done us a service in drawing our attention to what is actually going on in this field. Those who use SDOs find them helpful in improving medication compliance and, presumably, would defend their use. Some would argue for the virtues of openly linking the orders with their objectives - treatment. Others will argue that they work precisely because they are not declared as CTOs and achieve the same end by enabling engagement and persuasion through obligatory access. With our current knowledge-base no one is in a position to estimate confidently what the difference would be between a community treatment order and a community supervision order such as the SDO. What we can be confident about in the current climate is that evidence of significant variation in practice without either clinical justification or constructive dialogue weakens our profession's position in negotiations about legislation.

\section{References}

FRANKLIN, D., PINFOLD, V., BINDMAN, J., et al (2000) Consultant psychiatrists' experiences of using supervised discharge: results of a national survey. Psychiatric Bulletin, 24, 412-415.

NATIONAL SCHIZOPHRENIA FELLOWSHIP (1999) BetterAct Now!

NSF's views on the Mental Health Act Review. London: Nationa Schizophrenia Fellowship

ROYAL COLLEGE OF PSYCHIATRISTS (1993) Community Supervision Orders. Council Report CR18. London: Royal College of Psychiatrists.

Tom Burns Professor of Community Psychiatry, Section of Community Psychiatry, Department of General Psychiatry, St George's Hospital Medical School, JennerWing, CranmerTerrace, London SW17 ORE 